\title{
Policy Is Possible
}

\author{
Michael Villeneuve \\ Scholar-in-Residence \\ Canadian Nurses Association
}

The great American poet and artist Maya Angelou said, simply, "When you know better, you do better." I take that as both an observation and a duty. CJNL has a mission to help us in both the knowing and the doing, and - as the theme of the February 2011 national Nursing Leadership Conference challenged us - to think about the "So what? Now what?" questions of our time.

Unfolding before our eyes is the transition of the first wave of the baby boom into traditional retirement years. Already, some 1,000 Canadians a day turn 65, and there will be 10 million of us over that age by 2040 . On average, we will live longer, healthier lives than any generation in history. Daunting is the reality that, while many of us will do so in better health than any previous generation, much of our longevity will be accompanied by chronic health problems - in some cases, by complex and concurrent ones.

In a seminal speech in 2005 that laid out the landscape of human health and service delivery challenges for a generation, Sister Elizabeth Davis (then chair of the Canadian Health Services Research Foundation) teased that we, the baby boomers, are "the most selfish generation in human history" and dared the audience to "imagine what we will be like when we start to age and need health care" (Davis 2005). While being deliberately humorous, she was right that this generation has very different demands and expectations about healthy aging and how its members will live in old age. Putting one example succinctly at the recent Nursing Leadership Conference in Montreal, former MP Deborah Grey said, "We want home care, not care homes." 
The often-twinned issues of aging and chronic illness are but two of our challenges. Acute cardiovascular disease, cancer and trauma, with their effective but pricy surgical solutions, place huge demands on the country's human and physical resources. By some estimates, mental illness is second only to cardiovascular disease in its morbidity burden across society. And lying ahead is the prediction that more than 1 million Canadians will have dementia within a generation - a new case every two minutes by 2038 (Alzheimer Society of Canada 2010).

What kind of care will all these Canadians need? What are we willing to pay, and for what range of services? Who should provide it? Who will be ready and able to do so?

These threats and uncertainties are worrying to say the least, and they are looming large. However things unfold, the current Health Accord and transfer agreements come to their ends in 2014, and there is already a growing wave of dialogue across Canada about the future of healthcare. With all its challenges, this time offers nursing a window of opportunity to get out ahead of some of these curves and to plant our flag as leaders who can bring effective, satisfying solutions to some of these policy problems.

The Canadian Institute for Health Information (2010) tells us that some 13\% of all hospital days are taken up by alternate level of care (ALC) patients - put in plain English, Canadians who have health challenges that they can't resolve on their own, but have no other option than to turn to our expensive, acute, inpatient hospital beds. Nearly two-thirds of them stay more than a week, and a quarter more than a month. A third of those patients need quiet and compassionate endof-life care, but find themselves competing with acutely ill surgical patients for attention in busy hospital wards.

The treatment solutions of the mid-20th century were doctor- and hospitalfocused. Much of that system still works well for the acutely ill. But 50 years on, the ALC problem is symptomatic of the fact that that while "we know better," in some important ways we aren't doing better.

\section{So What? Now What?}

Speaking at the Canadian Association for Health Services Policy and Research conference in 2005, economist Robert Evans reminded us bluntly that "policy is possible." More recently, talking about health costs, he argued that they are "primarily a political, not an economic, problem," noting that, "Rising health costs are not a law of nature, like the tides. They are responsive to well-crafted policy" (Evans 2010). The same is true of fixing the ALC issue, and helping to manage the health problems that emerge in older age, and dealing with chronic and mental illness, and comforting the dying. Policy is possible. 
Leading in any of these agendas will necessitate a coordinated, strategic and multi-pronged approach by the profession. A critical element in our success will be the knowledge and political savvy of nurses in formal decision-making positions in governments and agencies such as the World Health Organization. To help us better understand these roles, their potential and challenges, my colleague Kathleen MacMillan and I have initiated contact with federal, provincial and territorial chief nursing officers, and with nurses who are current or former deputy and assistant deputy ministers, elected officials and appointed senators. Beginning in the next issue, $C J N L$ will feature a series of papers that will explore themes of success in those roles, as well as their pitfalls and worries. A concluding paper in 2012 will summarize the lessons from that year of work.

We are encouraged by the helpful response to our request from the nurse leaders who hold (or have held) these positions. We expect to generate a lively and valuable series that can inform our collective strategy heading into 2014 and beyond. We hope you will come back, encourage colleagues to read the journal, think things through with us and share feedback that will help us all to be stronger and more effective in our policy leadership - together.

\section{References}

Alzheimer Society of Canada. 2010. Rising Tide: The Impact of Dementia on Canadian Society. Ottawa: Author.

Canadian Institute for Health Information (CIHI). 2010. Health Care in Canada 2010. Ottawa: Author.

Davis, E. 2005. "Dory, Rainbow and Inukshuk: The Journey to a Strong Health System in Canada." Paper presented at the Canadian Health Services Research Foundation 7th Annual Workshop Leveraging Knowledge: Tools \& Strategies for Action, Montreal, QC.

Evans, R. 2010. “The TSX Gives a Short Course in Health Economics: It's the Prices, Stupid!” Healthcare Policy 6(2): 13-23. 